\title{
Representações Sociais do Suicídio para adolescentes de uma Escola Pública de Curitiba, Paraná, Brasil
}

\author{
Social representations of suicide for adolescents of a Public School \\ in the city of Curitiba, Paraná, Brazil
}

Patrícia Louise Kravetz (https://orcid.org/0000-0002-4734-3006) ${ }^{1}$

Bruna Chime Madrigal (https://orcid.org/0000-0002-7196-8292) ${ }^{1}$

Emily Ravaneda Jardim (https://orcid.org/0000-0001-5306-0275) ${ }^{1}$

Evelin Caroline de Oliveira (https://orcid.org/0000-0003-4007-4752) ${ }^{1}$

Juliana Guadalupe Muller (https://orcid.org/0000-0002-2282-8509) ${ }^{1}$

Vitória Maria Cardoso Prioste (https://orcid.org/0000-0003-0779-087X) ${ }^{1}$

Ana Claudia Wanderbroocke (https://orcid.org/0000-0002-2876-5326) ${ }^{1}$

Gislei Mocelin Polli (https://orcid.org/0000-0001-7254-7441) ${ }^{1}$

\footnotetext{
${ }^{1}$ Universidade Tuiuti do Paraná. R. Sydnei Antonio Rangel Santos 238, Santo Inacio. 82010-330 Curitiba PR Brasil.

pattyloukravetz@gmail.com
}

\begin{abstract}
This study seeks to understand the social representations (SR) of suicide among high school adolescents of a public school in Curitiba, such as the media influences on the construction of these SR. The research was performed using the qualitative method and structured around the tenets of Social Representation Theory. A total of 18 adolescents of both genders participated in the study, and data collection was conducted through the formation of focus groups. The material transcribed was analyzed by the Descending Hierarchical Classification method with the aid of the IRaMuTeQ program. It was possible to establish that the SR of the adolescents surveyed are linked to the relevance of positive interpersonal relationships when faced with the impact that suicide information causes. This predominantly defines the emotional state of the person receiving information, and the primordial hosting, listening and assistance relationships that are important for the content and manner in which situations involving suicide are reported by the media. Taking these considerations into account, new studies in this area are required to promote the development and construction of new perspectives and subsequent social empowerment through information, aiming at the enhancement of the mental health of school adolescents.
\end{abstract}

Key words Suicide, Adolescents, Social Representations, Media, School
Resumo Este estudo busca compreender as Representações Sociais (RS) do Suicídio entre adolescentes do Ensino Médio de uma Escola Pública de Curitiba, tal como as influências midiáticas sobre a construção dessas representações. A pesquisa foi realizada com utilização do método qualitativo, e orientada pelos pressupostos da Teoria das Representações Sociais. Participaram do estudo 18 adolescentes de ambos os gêneros, e a coleta de dados se deu por meio da formação de grupos focais. O material transcrito foi analisado pelo método de Classificação Hierárquica Descendente com auxílio do programa IRaMuTeQ. Foi possível considerar que as $R S$ dos adolescentes pesquisados giram em torno da relevância das relações interpessoais positivas diante do impacto que as informações sobre o suicídio causam, definindo, majoritariamente, que o estado emocional da pessoa que recebe informações, bem como as relações primordiais de acolhimento, escuta e auxílio se sobressaem ao conteúdo e forma com a qual situações envolvendo suicídio são relatadas pelas mídias. Diante dessas considerações, indicam-se novos estudos nessa área para que possa haver o desenvolvimento e construção de novas perspectivas e um consequente fortalecimento social através da informação, visando à promoção de saúde mental dos adolescentes escolares.

Palavras-chave Suicidio, Adolescentes, Representações Sociais, Mídias, Escola 


\section{Introdução}

O suicídio é um problema significativo de caráter social e de saúde pública. Entender a temática na dimensão social faz com que haja uma compreensão além dos fatores teóricos, tornando possível a elaboração de estratégias de intervenção e prevenção frente ao tema. Segundo a Associação Brasileira de Psiquiatria (ABP $)^{1}$, o suicídio pode ser definido pelo desejo consciente de tirar a própria vida e o entendimento de que a ação realizada pode resultar na morte. Além disso, também fazem parte do que é habitualmente chamado de comportamento suicida: os pensamentos, a ideação, os planos, a tentativa e o suicídio consumado.

Conforme a Organização Pan-Americana de Saúde (OPAS) ${ }^{2}$ aproximadamente $800 \mathrm{mil}$ pessoas morrem por suicídio no mundo a cada ano. Sendo a segunda principal causa de morte em pessoas da faixa etária de 15 a 29 anos. No Brasil, todos os anos são registrados cerca de 10 mil casos de suicídio ${ }^{3}$. Em setembro de 2017, o Ministério da Saúde ${ }^{3}$ lançou uma agenda estratégica de prevenção ao suicídio, que visa promover a redução de $10 \%$ do número de mortes por essa causa no Brasil até 2020.

A relevância da prevenção ao suicídio na promoção de saúde está diretamente relacionada com o tratar sobre o assunto, faz-se necessário informar e educar a comunidade para lidar com isso, aprimorar as formas de identificação, visando a redução da taxa de suicídio. Este é o ponto de partida para iniciar uma nova concepção social sobre a temática ${ }^{4}$. A Agenda Estratégica de Prevenção ao Suicídio do Ministério da Saúde ${ }^{3}$ aponta a necessidade do levantamento qualificado de pesquisas científicas que considerem os determinantes sociais de saúde com vistas a novas sugestões que agreguem a intervenção frente a prevenção desse fenômeno. Sendo assim, o estudo acerca das representações sociais do suicídio se desenvolve a partir da necessidade de estudos para maior conhecimento nesta área.

O sociólogo francês Durkheim ${ }^{5}$ argumentou no final do século XIX que o suicídio não poderia ser explicado e reduzido como um fenômeno estritamente individual, salientando que os aspectos sociais estão diretamente relacionados à temática. Atualmente, sabe-se que o suicídio é entendido em uma dimensão biopsicossocial de causas múltiplas, em que os aspectos psíquicos, sociais, culturais e biológicos interagem variavelmente. Para a $\mathrm{OPAS}^{2}$ o suicídio é uma questão complexa e é necessário que os esforços para a prevenção venham através da colaboração de múltiplos setores sociais, como saúde, educação, trabalho, mídias, políticas públicas etc. Afirmando que esses esforços precisam estar integrados, pois apenas uma abordagem não é capaz de dar conta de um problema tão complexo.

Para o desenvolvimento dessa pesquisa, foi utilizado o suporte teórico e metodológico da Teoria das Representações Sociais (TRS), desenvolvida por Moscovici. A TRS surgiu na Europa, a partir de uma pesquisa de Psicologia Social, realizada por Serge Moscovici, que objetivava investigar as Representações Sociais da Psicanálise. Tal conceito surge a partir da crítica à pesquisa psicológica individualizante, e visa o retorno à pesquisa psicossocial que considera o homem como conhecedor e transformador do conhecimento, mesmo que esse não seja formalizado ${ }^{6}$. Moscovici ${ }^{7}$ buscou explanar como os pensamentos se organizam e se estruturam frente ao contexto social. Para isso, acrescentou novos elementos à concepção de representações coletivas, desenvolvidas por Durkhein, fazendo com que a noção de representações sociais se situasse na interface entre a Psicologia e a Sociologia. As Representações Sociais (RS) se referem à maneira dos indivíduos pensarem e interpretarem o cotidiano, constituindo um conjunto de imagens que permitem interpretar suas vidas e a elas darem sentido. Ao considerar os projetos mentais subjacentes no estudo das Representações Sociais, leva-se em conta uma concepção de homem, baseada na Psicologia Social, cuja compreensão de mundo é repleta de significados e sentidos construídos ativamente, de maneira individual e em grupo - nas relações.

Além disso, podem ser compartilhadas como uma rede de conhecimentos, cuja elaboração se dá a partir das trocas sociais. Ao conjunto de crenças, valores, atitudes, opiniões e imagens que compõem as RS relacionadas a um objeto, ideia ou pessoa, Jodelet ${ }^{8}$ atribui a função de nortear pensamentos, percepções e comportamentos esperados diante de cada situação, contribuindo "para a construção de uma realidade comum a um conjunto social"s(p.22).

Com o aporte das RS, $\mathrm{Cabral}^{9}$ realizou uma pesquisa em Portugal com 82 adolescentes e verificou que o suicídio é pensado como uma forma de escape aos problemas cotidianos. Cremasco e Baptista $^{10}$ investigaram as RS do suicídio entre 77 estudantes de psicologia e encontraram dados semelhantes. O suicídio é considerado uma forma de fuga quando as pessoas não conseguem resolver os problemas. 
Ao entrevistar 22 pessoas com dependência química, Cantão e Lappann Botti ${ }^{11}$ perceberam que o suicídio, para estas pessoas, está relacionado ao descrédito pessoal, abandono da família, desespero e falta de fé. Ao analisar 91 comentários postados na internet sobre notícias relacionadas ao suicídio, Gomes-Valério et al. ${ }^{12}$ identificaram culpabilização das vítimas e associaram o ato suicida à falta de Deus.

Para compreensão do fenômeno do suicídio no contexto social, esse estudo também apresenta as influências que as mídias exercem na construção das Representações Sociais do Suicídio para os adolescentes pesquisados. $\mathrm{O}$ comunicar como um fator inerente ao existir humano, pode ser vivenciado de diferentes formas e afetado por quaisquer circunstâncias sociais, históricas, emocionais e relacionais. Como a mídia exerce um papel importante na formação das $\mathrm{RS}^{13}$, o mesmo se faz presente em sua relação com o fenômeno suicídio, essa comunicação presente nas relações possui influência direta na absorção e transmissão do conteúdo. Notícias sobre suicídio estabelecem um impasse: como informar sem trazer danos? Uma das medidas utilizadas pela OPAS ${ }^{2}$ para prevenir o suicídio, inclui a cobertura responsável dos meios de comunicação, fazendo-o de forma cautelosa. Assim como o modo de transmissão da mídia pode aumentar o número de casos de suicídio em uma população já vulnerável, o oposto também se faz verídico, podendo o noticiário ser via de acesso ao auxílio necessário para a mesma população, atuando como fator de prevenção e promoção de saúde. Tais reportagens podem servir de apoio a pessoas que são acometidas pela ideação suicida, sendo relevante, ao final das matérias, informar lugares onde é possível encontrar ajuda ou tratamento ${ }^{14}$.

Tendo isso em conta, a presente pesquisa foi desenvolvida no espaço escolar, escolhido por sua grande importância nos processos de aprendizagem, bem como na construção da socialização e formação intelectual ${ }^{15}$. A escola demonstra ser um notável lugar de construção de sentidos e das Representações Sociais, sendo essas uma das premissas defendidas e norteadoras desta pesquisa. Tendo em vista a importância demonstrável deste ambiente institucional e experiencial, esse estudo pretendeu identificar as Representações Sociais do Suicídio entre adolescentes de uma escola pública em Curitiba, bem como verificar as influências midiáticas frente a construção dessas Representações Sociais.

\section{Método}

O presente estudo trata-se de uma pesquisa de campo qualitativa, com embasamento teórico da área de Psicologia Social e da Teoria das Representações Sociais (TRS). A pesquisa qualitativa demanda o detalhamento do ambiente na qual se insere, permitindo assim, maior quantidade de informações para análise do tema, enriquecendo o estudo das relações sociais ${ }^{16}$.

A pesquisa foi submetida ao Comitê de Ética em Pesquisa com Seres Humanos (CEP) da Universidade Tuiuti do Paraná, e aprovado. Inicialmente, as pesquisadoras solicitaram a autorização da escola, que se localiza na cidade de Curitiba e faz parte da rede pública de ensino do estado do Paraná. Posteriormente, foi realizada a primeira visita do grupo com o intuito de familiarizar-se ao ambiente, a instituição foi selecionada pelas pesquisadoras por conveniência.

Participaram da pesquisa 18 estudantes do Ensino Médio, entre 15 e 21 anos, que foram selecionados aleatoriamente pela diretora da instituição. A coleta de dados ocorreu por meio de grupos focais. Os alunos foram divididos em três grupos de seis participantes, tendo como coordenadora uma das pesquisadoras. $\mathrm{O}$ grupo se deu por uma discussão aberta sobre um tema indutor relacionado ao suicídio, este guiado pela mediadora, com objetivo de evitar a mudança de foco. Após a coleta e análise de dados, as pesquisadoras realizaram um novo encontro com a proposta de feedback da pesquisa para os alunos participantes, além de abordar informações acerca da temática do suicídio e sua prevenção.

Antes da realização do grupo focal foi aplicado um questionário com questões para identificação dos participantes. O respeito ético em relação ao sigilo foi exposto durante a aplicação do questionário, visando a preservação da escolha livre dos participantes acerca das suas informações individuais, levando em consideração os documentos consentidos pelos responsáveis: Termo de Consentimento Livre e Esclarecido (TCLE) e Termo de Assentimento Livre e Esclarecido (TALE).

A técnica de grupo focal foi utilizada por ser um dos instrumentos mais eficientes na identificação das Representações Sociais, já que propicia a interação através do diálogo, compartilhamento de experiências mútuas e tomada de consciência ${ }^{17}$. Os estímulos para a discussão do grupo focal envolveram aspectos do suicídio e da mídia. Após a transcrição do conteúdo coletado, foi empregado o uso do software IRaMuTeQ (Inter- 
face de R pour les Analyses Multidimensionnelles de Textes et de Questionnaires), desenvolvido por Pierre Ratinaud, caracterizado por ser um programa de classificação hierárquica descendente (CHD), que visa a análise de conteúdos coletados através de segmentação e classes ${ }^{18}$.

\section{Resultados e discussão}

O corpus para análise deste estudo foi gerado a partir de respostas abertas dos 18 adolescentes participantes dos três grupos focais. As questões propostas foram: "Quando se fala em suicídio, o que vem à mente de vocês?"; "O que vocês sabem sobre o suicídio?”. Foram utilizadas 18 respostas que deram origem a 714 segmentos de textos (ST), dos quais $479(67,09 \%)$ foram utilizados na CHD. O corpus foi formado por 24.876 ocorrências de palavras.

Os resultados da CHD são apresentados no dendrograma (Figura 1) que aponta as classes e as relações estabelecidas entre elas. As respostas foram distribuídas em cinco classes. A primeira partição do corpus opõe a classe 5,1 e 3 às classes 2 e 4 ; a segunda partição opõe as classes 5 às classes 1 e 3 ; a terceira partição opõe a classe 1 à classe 3 ; e, por fim, a classe 2 à classe 4 . Especificamente, não foi perguntado aos adolescentes quanto à influência das mídias, uma vez que a maneira em que o grupo focal se realiza é manejada pelo discurso primariamente trazido pelos participantes, visando o menor grau de inferência por parte dos facilitadores deste.

A classe 5, caracterizada por relatos de suicídio, sugere o que influencia a pessoa a tirar sua vida e os métodos utilizados para tal. A classe 1 explana o apoio do núcleo familiar como fator de prevenção diante do tema. A classe 3 explora as influências do ambiente escolar. A classe 2 associa as influências das mídias diante da construção das Representações Sociais do suicídio. A classe 4 representa a importância da rede de apoio frente a essa demanda.

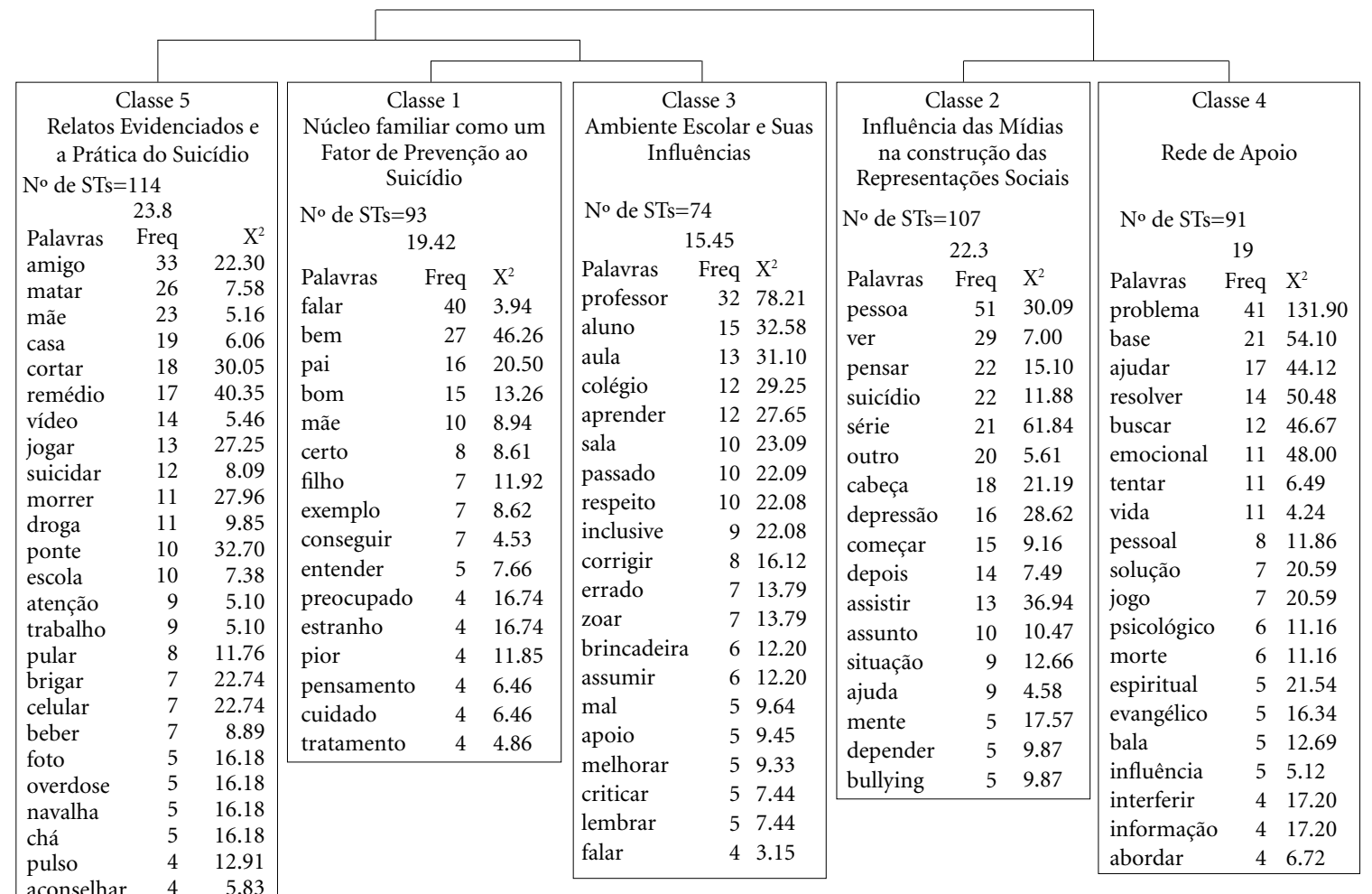

Figura 1. Dendrograma das RS do Suicídio. 


\section{Classe 5 - Relatos Evidenciados e a Prática do Suicídio}

A classe 5 foi composta por 114 ST, o que corresponde a 23,8\% do corpus. Algumas das palavras que compõem os segmentos são: cortar, droga, ponte, pular, navalha etc. A classe refere-se aos relatos dos alunos acerca da prática do suicídio e métodos mais utilizados para tal tentativa. Muitos dos participantes expuseram experiências relacionadas ao tema de modo pessoal, fazendo referência a acontecimentos na família, com amigos, irmãos, e experiência individual de tentativa de suicídio:

A minha irmã jogou baleia azul, só que ela não chegou a se suicidar, mas pegamos ela se cortando com a navalha (Part. 15, gen. masc. 17 anos).

O suicídio é a segunda principal causa de morte no mundo entre a população jovem de 15 a 29 anos $^{2}$. Considerado um problema de saúde pública, a Organização das Nações Unidas ${ }^{19}$ aponta que a tentativa ou ato suicida possui uma relação estreita com transtornos mentais, depressão, comportamentos impulsivos, dificuldades financeiras e problemas relacionais amorosos ou familiares. Com isso, são correspondentes os relatos dos participantes, que abordam conteúdos que tratam de fatores que podem induzir o sujeito a cometer o ato, salientando que a maior parte da população participante tem conhecimento de um ou mais indivíduos que cometeu o ato suicida ou realizou a tentativa do mesmo.

No estudo de Braga e Dell'Aglio ${ }^{20}$, os autores discutem aspectos relacionados aos fatores de risco e características epidemiológicas do suicídio na adolescência. Os resultados apontam que os principais fatores de riscos envolvidos são:

Presença de eventos estressores ao longo da vida, exposição a diferentes tipos de violência, uso de drogas lícitas e/ou ilícitas, problemas familiares, histórico de suicídio na família, questões sociais relacionadas à pobreza e à influência da mídia, questões geográficas e depressão $o^{20}$ (p.11).

Dentre os métodos mais utilizados para a tentativa do suicídio pelo público adolescente está a autointoxicação, porém, para a efetivação de fato do ato suicida, os meios manuseados com maior frequência são o enforcamento, uso da arma de fogo e autointoxicação ${ }^{20}$. Estes dados correspondem a uma significativa parte dos relatos dos participantes deste estudo que manifestaram conhecimentos de pessoas próximas que efetuaram alguma dessas práticas.

\section{Classe 1 - Núcleo Familiar como um fator de prevenção ao Suicídio}

A classe 1 foi composta por 93 ST, representando $19,42 \%$ do corpus. Ela faz referência ao relevante apoio do núcleo familiar frente à prevenção do suicídio. Algumas das palavras que formam os segmentos dessa classe são: pai, filho, mãe, exemplo, entender etc. Nessa classe, percebe-se que para os pesquisados, o apoio e o diálogo estabelecido nesse contexto são tidos fatores importantes na prevenção do suicídio. Foram citados alguns relatos pessoais sobre tentativas de suicídio, nas quais fica exposta a necessidade do apoio, diálogo e escuta empática da família diante desse fenômeno:

Acho que também vai da criação dos pais. Os pais dão a liberdade do filho chegar e falar: vamos conversar, o que que está acontecendo... Tem uns pais que nem tem tempo para isso (Part. 6, gen. fem. 17 anos).

Frente a uma rede de apoio mais próxima, é notável que a importância da família como um fator de proteção, principalmente quando se trata de crianças e adolescentes, pois o núcleo familiar representa um dos contextos sociais mais próximos do sujeito. Schneider e Ramires ${ }^{21}$, pesquisaram a respeito dos vínculos parentais e a rede de apoio social em 11 adolescentes que estavam em quadros depressivos e que tiveram algum tipo de ideação suicida. Os estudos apontaram que a maioria desses participantes possuía, em alguma medida, um vínculo inadequado com os pais, visto que na pesquisa predominaram as percepções de cuidados insuficientes pelas figuras parentais. Os autores concluíram, portanto, sobre a necessidade de o grupo familiar configurar-se como um facilitador e promotor de saúde mental.

Os relacionamentos interpessoais positivos e os laços afetivos oferecem uma maior proteção ao paciente com ideação suicida, enquanto relacionamentos conflituosos e violentos, somado ao histórico familiar relacionado ao suicídio, indicam risco ${ }^{22}$. É possível salientar a relevância de trabalhos que promovam o fortalecimento dos vínculos parentais, assim como as redes de apoio social frente à prevenção do suicídio, já que a família possui representação fundamental dentro de seu papel relacional em manejo do acompanhamento do sujeito ${ }^{1}$.

Classe 3 - Ambiente escolar e suas influências

A classe 3 foi composta por 74 ST, representando $15,45 \%$ do corpus, o qual faz referência ao 
ambiente escolar e suas influências. Os segmentos que compõem essa classe são formados por algumas palavras, como: professor, aluno, colégio e aprender. Nessa classe, denota-se que as trocas sociais que ocorrem dentro do ambiente escolar, juntamente do conjunto de crenças, valores e opiniões comuns através do relacionamento com os professores e das amizades - sejam elas dentro ou fora da escola - são fatores que podem influenciar, positiva ou negativamente, nos comportamentos tanto pessoais quanto coletivos. Ou seja, assim como assinala Jodelet ${ }^{8}$ o desenvolvimento das relações dentro de uma realidade partilhada norteia pensamentos, percepções e comportamentos. Um ST ilustra o conteúdo da classe:

Às vezes, a pessoa acaba faltando uma semana inteira e o professor nem sequer pergunta se você está bem, o que está acontecendo. Então, eu acho que isso é uma coisa que o colégio poderia mudar (Part. 18, gen. masc., 16 anos).

Os relatos que norteiam essa classe são caracterizados pela falta de atenção por parte do corpo docente e da instituição frente a problemas dos alunos, como por exemplo: motivos de ausência em sala ou pouca atenção durante as aulas. Afirmando, assim, uma negligência daqueles que deveriam demonstrar, pela visão dos alunos participantes, uma preocupação com os adolescentes. Moreira e Bastos $^{23}$ sinalizam a necessidade dos profissionais da educação, juntamente com profissionais da saúde - médicos, psicólogos, enfermeiros e assistentes sociais - atualizarem seus conhecimentos, visando um aperfeiçoamento da escuta e da comunicação em sala de aula a fim de abordar assuntos voltados à vida, morte, doenças mentais, sofrimentos, formas de violência e condutas destrutivas.

Os relatos trazidos pelos estudantes apontam situações em que alguns alunos manifestam julgamentos ou desvalorização dos sentimentos verbalizados por pessoas que apresentam ideação suicida. Algumas ações podem caracterizar a prática de bullying, que é descrito por Silva ${ }^{24}$ como ações de cunho agressivo, intencionais e repetitivas, que a princípio não possuem motivações e podem ser praticadas por uma ou mais pessoas, com o objetivo de amedrontar ou intimidar a vítima, sendo os agressores de ambos os gêneros. Para esse autor, uma das piores consequências que podem estar ligadas ao bullying é o suicídio.

Esta classe, portanto, faz referência a necessidade do ambiente escolar ser um espaço de conscientização, bem como postula Saviani ${ }^{25}$. Uma vez que esse ambiente perscruta o processo de construção de sentidos, possui da mesma forma, uma responsabilidade no tratar do tema suicídio. Houve a verbalização por alguns participantes sobre a necessidade de acompanhamento psicológico no ambiente escolar. Frente a isso, alguns autores reforçam a importância da atenção destinada aos estudantes, com prestação de serviços de assistência psicológica durante a fase escolar ${ }^{26}$. Ainda sobre o olhar necessário para contexto educacional, Wanzinack et al. ${ }^{27}$ afirmam que tal ambiente é favorável para o trabalho de promoção de saúde.

\section{Classe 2 - Influência das Mídias na construção das Representações Sociais}

A classe 2 foi composta por 107 ST, representando $22,3 \%$ do corpus. Tal classe se refere à influência das mídias na construção das Representações Sociais do fenômeno do suicídio. As principais palavras formadoras dos segmentos dessa classe são: série, assistir, depressão, mente etc. Foi possível perceber que os pesquisados possuem a crença de que as mídias possuem um papel norteador quanto à decisão de cometer o ato suicida ou não. Na descrição desses segmentos de textos, foram citados diversos relatos com variação de opinião entre os participantes, variação esta que oscilava entre a opinião de enxergar a mídia tanto como um meio de prevenção quanto como um fator de risco. Um exemplo citado foi quanto à série americana produzida pela Netflix 13 Reasons Why (Os 13 Porquês), a qual conta a história de uma adolescente que comete suicídio, como assinalam os exemplos:

Então vai muito da pessoa. Se a pessoa tem uma mente aberta... se aquela pessoa que é totalmente fechada não se abre com ninguém for assistir uma série dessa, realmente vai prejudicar (Part. 6, gen. fem. 17 anos).

A influência direta da mídia depende não somente de como a pessoa absorve as informações ali transmitidas, como assinalam os participantes, mas também de como é exposto o fenômeno nesse meio de comunicação. Rodrigues e Corrêa ${ }^{28}$ enfatizam que os meios de comunicação são ferramentas utilizadas no processo de construção e expressão de sentido social. Assim, lidam com as representações sociais que formam entendimentos dos grupos acerca do campo subjetivo e coletivo. Ou seja, influenciam diretamente na constituição da visão social e da autoimagem.

Da mesma forma que a maneira da mídia transmitir seus conteúdos possui a possibilidade de aumentar o número de casos de suicídio, ela também pode ser via de acesso de divulgação 
de informações. Rodrigues e Corrêa ${ }^{28}$ alertavam sobre o não comprometimento da mídia com os fatos científicos, tendo aspectos benéficos e maléficos; ainda que os diferentes tipos de saberes inseridos no contexto midiático sejam informativos, existe a vigente necessidade da cautela quanto ao modo de noticiar estas informações e à situação individual daquele que as absorve.

Há sugestões de como abordar o suicídio em noticiários, fazendo-o de forma cautelosa em relação a amigos e familiares enlutados e não detalhando o método suicida. Considerando que noticiar um conteúdo detalhado pode encorajar pessoas que estão vulneráveis ao suicídio a planejá-lo e cometê-lo, faz-se necessária a atenção para não romantizar ou tornar o suicídio um ato de coragem, além de não ressaltar reações positivas $^{14}$.

Sendo assim, pode-se afirmar que a mídia apresenta-se exercendo um grande papel na construção de influência educacional, nas ações cotidianas e nos comportamentos dos sujeitos. Segundo Polli e Camargo ${ }^{13}$ a temática das representações sociais tinham o compromisso de investigar as influências dos meios de comunicação na construção das RS. Estes estudos explicitam tal atuação no discurso social pluralista. Desta forma, as reflexões coletivas compartilhadas através das redes evidenciam a mídia representando um considerável instrumento a ser pesquisado, justamente por conta de seu alto nível de influência social.

\section{Classe 4 - Rede de Apoio}

A classe 4 foi representada por 91 ST, o que se refere a $19 \%$ do corpus. Apresentam-se, nos segmentos de texto, palavras como: problema, base, ajudar, resolver, buscar, emocional, tentar. A presente classe expressou a importância da formação de vínculo, do acompanhamento e da escuta de profissionais da saúde para com sujeitos que vivenciam e possuem ideação suicida. Nas falas dos adolescentes, notou-se a necessidade de ter uma rede de apoio para a prevenção do ato. A vulnerabilidade desses indivíduos pode referir-se ao contexto social inserido, ou também a transtornos psíquicos, sendo este um potencial relevante para os atos de suicídios cometidos ${ }^{29}$.

Teng e Pampanelli ${ }^{22}$ indicam que os cuidados parentais no desenvolvimento pessoal do indivíduo são relevantes e por este motivo necessitam de fortalecimento através de uma formulação de rede de apoio saudável, o que inclui não apenas o afeto, mas a disposição empática na construção de um diálogo, tais aspectos possuem potencial preventivo na construção da representação social do suicídio para os adolescentes pesquisados.

Segundo a $\mathrm{OPAS}^{2}$, são fatores protetivos: relacionamento e apoio familiar positivo; relações sociais e integração relacional, autoconfiança, ser ouvido e ser aconselhado; bom relacionamento com colegas nas comunidades participantes (com professores e outros adultos), ajuda de pessoas que são referenciais (envolvendo aspectos sociais, demográficos e culturais). Portanto, a conceituação de rede de apoio abrange os aspectos familiares, sociais, profissionais e estudantis. Isto é, a qualquer área da vida do ser humano que possa lhe trazer a noção de um acolhimento diante de um sofrimento psíquico. Um ST demonstra o conteúdo da classe:

Eu acho que as pessoas se cortarem e tentarem suicídio é uma forma da pessoa buscar ajuda, porque não é fácil você chegar em uma pessoa e falar que você precisa de ajuda, ninguém consegue fazer isso (Part. 10, gen. masc. 18 anos).

Com isso, considera-se a relação desta classe com a importância dos relacionamentos interpessoais, bem como das trocas de experiências entre amigos, orientações de familiares ou profissionais, representados como fortalecedores sociais e fundamentais para escuta do sofrimento individual, visando a prevenção do suicídio e da saúde mental ${ }^{30}$.

Considerando a necessidade de construção da identidade no período da adolescência, mediante desconstruções e reconstruções biológicas, sociais e psicológicas pertinentes a essa fase, a interação social faz-se essencialmente relevante para tal constructo. Diante disso, tem-se uma busca por identidade social, relacionado ao pertencimento que se define a partir da diferença do outro. Além de, por essa razão, os grupos de amizades serem formadores e organizadores do pensar adolescente, a participação dos adultos no processo também é tida como apoio fundamental, embasando a estrutura necessária sobre a qual constrói-se o pensar, por meio de regras e normas do social ${ }^{30}$. A esfera psicológica, ao longo do desenvolvimento do indivíduo, é frequentemente determinada, modificada e influenciada pelo contexto social.

\section{Representações Sociais do Suicídio para os Adolescentes pesquisados}

As representações sociais do suicídio para os adolescentes participantes deste estudo envolvem os aspectos mencionados nas classes, tais quais: 
relatos evidenciados e a prática do suicídio (5), núcleo familiar como fator de prevenção do suicídio (1), ambiente escolar e suas influências (3), influência das mídias na construção das representações sociais (2) e rede de apoio (4).

Experiências de ideações suicidas e métodos para realização do ato, verbalizados pelos adolescentes, indicam a presença de conhecimentos pessoais acerca do suicídio. É possível entender que a maneira com que a história de vida do adolescente se constitui abarca a perspectiva de que as suas relações expõem o conhecimento prévio acerca do suicídio ${ }^{27}$. Sendo assim, denota-se que as relações cultivadas nas experiências passadas e as expectativas perante as mesmas influenciam diretamente na compreensão do que representa o suicídio para estes sujeitos, tal fato comprovase também pela observação da importância dada ao que o outro espera, nas falas dos adolescentes participantes.

Valores compartilhados no ambiente escolar auxiliam na construção das RS do suicídio. Estes são partilhados através de referenciais adotados de acordo com as identificações pessoais. O que resulta na identidade grupal das amizades formuladas nas escolas, que também são influenciadas pelos professores, que assumem a função de influenciadores ${ }^{31}$.

Devido à adolescência ser um período de muitos conflitos internos, ressignificações, questionamentos e instabilidades ${ }^{32}$, a maneira com que a instituição educacional reage diante de tais transformações acaba por fazer parte da elaboração do sentido acerca do suicídio, uma vez que é o ambiente em que se faz presente todos os dias. Para Wanzinack et al. ${ }^{27}$, esta elaboração pode revelar tanto uma negligência escolar diante do tema quanto uma responsabilidade de prevenção do ato. A medida como o fenômeno do bullying é tratado neste local também é um aspecto que manifesta se a escola está acolhendo esse sujeito ou o afetando negativamente.

De acordo Minayo et al..$^{33}$, a forma de tratar o tema e a sua banalização pelas mídias pode minimizar o impacto de como o suicídio é representado socialmente, tornando as mídias como fatores de risco. Entretanto, da mesma forma, como demonstrado através do discurso apontado pelos adolescentes na pesquisa, essa influência do conhecimento trazido pelas informações destes meios pode refletir um aspecto positivo também. Sendo assim, de maneira benéfica ou maléfica, a mídia participa ativamente na composição significante das RS do suicídio. Isto posto, é de extrema importância, como bem aponta a $\mathrm{OPAS}^{2}$, que exista cautela na maneira com que se transmite as informações, havendo respeito, responsabilidade e diminuição da banalização do tema.

Barbosa et al..$^{34}$ apontam para uma proximidade receptiva acerca do sentimento do outro, seja no que tange às mídias, ou dentro do contexto familiar, nas redes de apoio e inclusive nos ambientes frequentados pelos adolescentes (no caso desta pesquisa, a escola como foco de análise) a fim de que o suicídio não seja tomado como tabu e nem seja banalizado.

É necessário propagar sensibilização para um olhar de respeito e consideração, em que o medo de ser escutado possa ser superado através de sofrimento acolhido, pois para mitigar os fatores de risco, existem os fatores de proteção. Tais informações levam ao entendimento de que cada aspecto citado pode funcionar como influenciador da construção da RS acerca do suicídio. Deste modo, deve-se tem em conta que não pode haver um caminho único, no sentido de que tudo depende de como cada história, de cada indivíduo e suas relações, são formulados e enfrentados no decorrer de suas vidas.

Analisando todos os relatos, temas e considerações pode-se concluir que para esse grupo ficou evidenciado que as relações que o sujeito cultiva possuem grande importância na tomada de decisão entre cometer ou não o suicídio, decisão esta entendida pelos participantes como um ato de fuga da realidade, do sofrimento e/ou dos problemas. A família, amigos e o ambiente escolar podem servir como fator de proteção, rede de apoio, ou negligenciar este indivíduo e todo seu sofrimento pode funcionar como fator de risco.

Para esses adolescentes, qualquer indivíduo está exposto a doenças mentais - como depressão - ou situações que o motive a pensar em suicídio, o que difere uma pessoa suicida de outra que busca apoio está nessas relações e de como essas o acolhem. Aquele que expressa seu sofrimento e é amparado, seja pela família, amigos ou ambiente escolar apresentar menor propensão de cometer $\mathrm{o}$ ato, porém, aquele que verbaliza suas queixas, e é visto com julgamento, não é acolhido e não estabelece rede de apoio possui grandes chances de cometer o suicídio ${ }^{22}$.

Outro ponto abordado pelos participantes foi a influência que as mídias exercem frente a este tema, no entanto as opiniões expostas acerca destas influências se mostraram diversas. Enquanto alguns adolescentes afirmavam que as mídias, ao tratarem do assunto, podem incentivar o sujeito em situação de risco cometer o ato, outros as viam como instrumento de apoio, tanto para sui- 
cidas, como para pessoas próximas ou que já estiveram em contato com relatos de ideações suicidas. Consideraram que quando se é transmitido e abordado esse assunto nas mídias, é necessário que haja um auxílio frente a divulgação de informações acerca dos lugares onde buscar ajuda. Foi enfatizada também a necessidade da construção de uma rede de apoio para esses sujeitos fragilizados.

Os adolescentes mostraram interesse pela temática, em alguns momentos com muita proximidade do saber científico entrelaçado ao seu conhecimento e ao desejo de falar sobre. Alguns buscaram a empatia ao relatar casos, esboçando assuntos variados, em sua maioria relacionados ao contexto escolar e familiar. Os adolescentes conseguiram visualizar a dimensão que tal assunto possui, em conjunto, refletiram sobre os fatores de risco e proteção, além também, da exposição dada à importância de se falar sobre o suicídio. O que indica que o tema pode ser abordado nas escolas por profissionais qualificados de forma não só a orientar, como também identificar alunos em sofrimento que necessitem ser acolhidos.

\section{Considerações finais}

Conforme referido nas cinco classes, as Representações Sociais dos adolescentes são construídas enquanto influenciadas por relatos de ideação suicida de outros, ou efetuação do ato por algum conhecido, além de expressões midiáticas sobre o tema, relações estabelecidas no ambiente escolar, mas principalmente pelo ciclo familiar.

A respeito da rede de apoio, também citada nas classes, as relações familiares foram apresentadas como vital fonte de impacto: como apoio quando construídas positivamente, e como fator prejudicial à saúde emocional quando tais relações denotam desamparo, negligência ou abuso, podendo facilitar a tentativa ou o ato do suicídio. Assim, os adolescentes expressaram a relevância das relações diante do impacto que as informações sobre o tema causam, definindo, majoritariamente, que o estado emocional da pessoa que recebe informações, bem como as relações primordiais de acolhimento, escuta e auxílio se sobressaem ao conteúdo e forma com a qual situações envolvendo suicídio são relatadas.

As limitações encontradas para a realização deste estudo, se devem majoritariamente à es- cassez de estudos sobre o suicídio, por ainda ser tratado como tabu na sociedade. Tal limitação define-se pela reduzida literatura sobre os assuntos abordados na pesquisa. Ao abordarmos a escola, verificou-se a abertura para a realização do projeto, refletindo a necessidade social de diálogo entre profissionais, alunos e professores sobre o tema e suas relações e indicando a grande demanda de acolhimento para com o sofrimento psíquico da comunidade escolar.

Diante da aceitação institucional, indicam-se novos estudos nessa área para que possa haver o desenvolvimento e construção de novas perspectivas e um consequente fortalecimento social através da informação. Além disso, seria de grande valia um estudo comparativo entre instituições de ensino público e privado, para analisar se há divergências no modo de pensar o suicídio em diferentes camadas da sociedade. Destaca-se o potencial de ampliação do projeto para demais escolas, visando a promoção de saúde aos adolescentes em idade escolar.

\section{Colaboradores}

PL Kravetz trabalhou na concepção, revisão bibliográfica acerca do tema, coleta e análise de dados, discussão de resultados e redação final. BC Madrigal trabalhou na concepção, revisão bibliográfica acerca do tema, coleta e análise de dados, discussão de resultados e redação final. ER Jardim trabalhou na concepção, revisão bibliográfica acerca do tema, coleta e análise de dados, discussão de resultados e redação final. EC Oliveira trabalhou na concepção, revisão bibliográfica acerca do tema, coleta e análise de dados, discussão de resultados e redação final. VMC Prioste trabalhou na concepção, revisão bibliográfica acerca do tema, coleta e análise de dados, discussão de resultados e redação final. JG Muller trabalhou na revisão bibliográfica acerca do tema, coleta e análise de dados, discussão de resultados e redação final. GM Polli trabalhou na concepção, na análise de dados e na redação final. ACN Wanderbroocke contribuiu na discussão dos resultados e realizou revisão final. 


\section{Referências}

1. Associação Brasileira de Psiquiatria (ABP). Suicídio: informando para prevenir. Brasília: CFM/ABP; 2014.

2. Organização Pan-Americana da Saúde (OPAS). Suicídio é grave problema de saúde pública e sua prevenção deve ser prioridade. Brasília: OPAS; 2018.

3. Brasil. Ministério da Saúde (MS). Agenda estratégica de Prevenção do Suicídio. Brasília: SUS/MS; 2017.

4. Centro de Valorização da Vida (CVV). Programa de Prevenção ao Suicídio e Apoio Emocional. CVV; 2017. Disponível em: https://www.cvv.org.br/

5. Durkheim É. O Suicídio: Estudo de Sociologia. São Paulo: Martins fontes; 2000.

6. Polli GM, Camargo BV. A teoria das representações sociais e a abordagem estrutural. In: Segata J, Machado N, Mandroi EC, Goetz ER, editores. Psicologia: Inovações. Rio do Sul: Editora Unidavi; 2010. p. 13-41.

7. Moscovici S. On social representation. In: Forgas JP, editor. Social Cognition. Londres: Academic Press; 1982. p. 181-209.

8. Jodelet D. Representações sociais: um domínio em expansão. In: Jodelet D, editor. As representações sociais. Rio de Janeiro: EdUERJ; 2001. p. 17-44.

9. Cabral CAA. Representações Sociais do Suicídio na Adolescência. Viseu: Escola Superior de Educação de Viseu; 2015.

10. Cremasco GS, Baptista MN. Depressão, motivos para viver e o significado do suicídio em graduandos do curso de psicologia. Estud Interdisciplinares Psicol 2017; 8(1):22-37.

11. Cantão L, Lappann Botti NC. Representação social do suicídio para pessoas com problemas relacionados ao uso de drogas. Avances Enfermería 2017; 35(2):148158.

12. Gomes-Valério JO, Leite MCP, Oliveira MBL, Andreza MJC, Freitas METP. Análise de comentários na internet como objeto de estudo da representação social do suicídio. Journal of Health Connections. 2018;6(5):43-57.

13. Polli GM, Camargo BV. Representações Sociais do meio ambiente para pessoas de diferentes faixas etárias. Psicol Rev 2016; 22(2):392-416.

14. Associação Brasileira de Psiquiatria (ABP). Conselho Federal de Medicina (CFM). Comportamento suicida: conhecer para prevenir, dirigido para profissionais de imprensa. São Paulo: Editora ABP; 2017.

15. Souza MPR. Psicologia Escolar e políticas públicas em Educação: desafios contemporâneos. Em Aberto 2010; 23(83):129-149.

16. Gibbs G. Análise de dados qualitativos. Porto Alegre: ArtMed; 2009.

17. Nóbrega DO, Andrade ÉR, Melo ESN. Pesquisa com grupo focal: contribuições ao estudo das representações sociais. Psicol Soc 2016; 28(3):433-441.

18. Camargo BV, Justo AM. IRAMUTEQ: Um Software Gratuito para Análise de Dados Textuais. Temas Psicol 2013; 21(2):513-518.

19. Nações Unidas Brasil (ONU-BR). Um suicídio ocorre a cada 40 segundos no mundo, diz OMS [Internet]. [acessado 2019 Mar 22]. Disponível em: https://brasil. un.org/pt-br/84115-um-suicidio-ocorre-cada-40-segundos-no-mundo-diz-oms

20. Braga LL, Dell'Aglio DD. Suicídio na adolescência: fatores de risco, depressão e gênero. Contextos Clínicos 2013; 6(1):2-14.
21. Schneider ACN, Ramires VRR. Vínculo parental e rede de apoio social: relação com a sintomatologia depressiva na adolescência. Aletheia 2007; 26:95-108.

22. Teng CT, Pampanelli MB. O Suicídio no contexto psiquiátrico. Rev Bras Psicol 2015; 2(1):41-51.

23. Moreira LCO, Bastos PRHO. Prevalência e fatores associados à ideação suicida na adolescência: revisão de literatura. Psicol Escolar Educacional 2015; 19(3):445453.

24. Silva ABB. Bullying: Cartilha 2010 - Projeto justiça nas escolas. Brasília: CNJ; 2015.

25. Saviani D. Escola e democracia: teorias da educação, curvatura da vara, onze teses sobre educação e política. Campinas: Autores Associados; 2008.

26. Araújo LC, Vieira KFL, Coutinho MPL. Ideação suicida na adolescência: um enfoque psicossociológico no contexto do ensino médio. Psico-USF 2010; 15(1):4757.

27. Wanzinack C, Temoteo A, Oliveira AL. Mortalidade por suicídio entre adolescentes/ jovens brasileiros: Um estudo com dados secundários entre os anos de 2011 a 2015. Rev Eletr Diversos 2017; 10(2):106-117.

28. Rodrigues CML, Corrêa CR. O sofrimento é opcional": uma análise do uso do conceito de resiliência no trabalho na mídia para o grande público. Outras Palavras 2016; 12(1):32-42.

29. Kohlrausch E, Lima MADS, Abreu KP, Soares JSF. Atendimento ao comportamento suicida: concepções de enfermeiras de unidades de saúde. Cien Cuidado Saúde 2008; 7:4.

30. Peres AL, Nicoli BS, Crespo BRC, Rodrigues CAS, Rodrigues ESS, Zoppé GSS, Cabral HG. Morte silenciada: o suicídio e a representação social. Rev Ambiente Acadêmico 2016; 2(1):109-124.

31. Vieira KFL, Coutinho MPL. Representações sociais da depressão e do suicídio elaboradas por estudantes de psicologia. Psicol Cien Profissão 2008; 28(4):714-727.

32. Cequeira-Santos E, Melo-Neto OC, Koller SH. Adolescentes e adolescência. In: Habigzang LF, Diniz E, Koller SH, editores. Trabalhando com Adolescentes: Teoria e Intervenção Psicológica. Porto Alegre: Artmed; 2014.

33. Minayo MCS, Pinto LW, Assis SG, Cavalcante FG, Mangas RMN. Tendência da mortalidade por suicídio na população brasileira e idosa, 1980-2006. Rev Saúde Pública 2012; 46(2):300-309.

34. Barbosa FO, Macedo PCM, Silveira RMC. Depressão e o suícido. Rev SBPH 2011; 14(1):233-243.

Artigo apresentado em 08/04/2019

Aprovado em 07/06/2019

Versão final apresentada em 09/06/2019

Editores-chefes: Romeu Gomes, Antônio Augusto Moura da Silva 